\title{
In search of the tendon holy grail: predictable clinical outcomes
}

\author{
Jill Cook
}

What is your first reaction when you find out your next patient has a long-term tendinopathy? I suspect you want to hide or get an urgent phone call that drags you away from the practice. You know that the person will have tried multiple interventions, probably had several injections, read all the literature about treatments for tendinopathy on the internet and want an immediate and lifelong cure. You also know that your assessment will take well into your next patient's time allotment and even then it will remain difficult to prioritise treatments and to explain the rationale behind your plan to the patient. Even as a tendon researcher and part-time clinician whose practice consists solely of tendinopathy patients, my reactions to chronic tendinopathy patients are similar.

\section{WHY ARE TENDONS SO DIFFICULT TO TREAT?}

Tendon is incredibly complex tissue that refuses to behave in any sort of structured reparative way or respond to clinical interventions with consistent outcomes. We are very familiar with the conundrums that tendinopathy presents. Place load on an already sore tendon and it often becomes more painful, but resting it does not offer any long-term relief. Exercising tendons eccentrically seems to improve them; concentric exercise of identical load does not have the same effect! How many clinical explanations are there for why eccentric exercise is effective? I have heard many, including the effect of stretching when loaded, the range of movement that the tendon goes through, and even that eccentric exercises stimulate healing. A review in this issue ${ }^{1}$ (see page 242) might help you explain to your patient why eccentric movements are better than concentric. You'll appreciate the paper that asks what aspects of the standard eccentric exercise programme have the most effect-I suspect you might be surprised by the answers ${ }^{2}$ (see page 276).

Correspondence to: Jill Cook, Centre for Physical Activity and Nutrition Research, Deakin University, Melbourne, Victoria, Australia; jill.cook@deakin.edu.au

\section{INTERESTING ASSOCIATIONS WITH TENDINOPATHY: EXCESS BODY FAT}

Have you noticed that patients who you think should respond quickly often turn out to be non-responsive and sometimes a patient with a chronic, apparently challenging tendon problem recovers swiftly? There is increasing evidence of an association between tendinopathy and body composition. ${ }^{3}$ It seems having more body fat and suffering from its consequences (such as increased blood glucose) are associated with tendinopathy. In this issue, Longo et al report that glucose levels are indeed higher in those with rotator cuff tears when compared with other orthopaedic patients ${ }^{4}$ (see page 284). So when your next chronic tendinopathy patient is overweight and has impending Type II diabetes you might anticipate a poorer outcome. Paradoxically and frustratingly, it seems that those patients whose health can benefit most from exercise are those who might struggle to get over tendinopathy and get on with exercise.

\section{LOTIONS, POTIONS AND INJECTIONS}

The truism that the more treatments that exist for any particular condition, the less effective are any of those treatments holds true for tendinopathy. Tendinopathy treatment abounds with things to rub onto, inject into, or swallow, to improve (usually) tendon pain. Consistent with this, our authors report on the effect of injecting cells and dextrose into tendons ${ }^{56}$ (see pages 293 and 303), as well as targeting tendons externally using extracorporeal shock wave therapy $(E S W T)^{7}$ and glyceryl trinitrate $^{8}$ (see page 299). These interventions appear effective in reducing pain and improving imaging appearance, something we all want for our patients.

\section{"STANDARD" CLINICAL TESTS - TIME FOR RETHINKING?}

If you have the time and energy to incorporate new perspectives into your already overcrowded cortex this issue has two papers to digest; one suggests that all standard tests for rotator cuff tendinopathy are clinically inaccurate - fundamentally a waste of time!' (see page 259). But don't fear - the authors provide an alternative approach. You can also read about the new integrative model of elbow assessment ${ }^{10}$ (see page 252). New assessment strategies, aside from making our clinical assessments shorter and more pertinent (always a good thing), introduce us to new ways of thinking about and approaching tendinopathy. This is essential given that the tried and tested regimes so often let us down. BJSM aims to be "translational" - turning research into practice $^{11}$ - and these integrative models for patients with elbow or rotator cuff tendinopathy provide clinicians with a range of new options.

So, although this issue of BJSM can't answer all of your questions, the contributions may help your understanding of tendinopathy, and, importantly, provide tips to help you manage patients. The challenge for BJSM in the future will be to integrate relevant research into useable clinical guidelines to treat tendinopathy.

\section{Competing interests: None declared.}

Br J Sports Med 2009;43:235.

doi:10.1136/bjsm.2009.058578

\section{REFERENCES}

1. Rees JD, Wolman RL, Wilson A. Eccentric exercises why do they work, what are the problems and how can we improve them? Br J Sports Med 2009;43:242-6.

2. Allison GT, Purdam C. Eccentric loading for Achilles tendinopathy - strengthening or stretching? $\mathrm{Br} J$ Sports Med 2009;43:276-9.

3. Gaida JE, Cook JL, Bass SL. Adiposity and tendinopathy. Disabil Rehabil 2008;30:1555-62.

4. Longo UG, Franceschi F, Ruzzini L, et al. Higher fasting plasma glucose levels within the normoglycaemic range and rotator cuff tears. $\mathrm{Br} \mathrm{J}$ Sports Med 2009;43:284-7.

5. Connell D, Datir A, Alyas F, et al. Treatment of lateral epicondylitis using skin-derived tenocyte-like cells. $\mathrm{Br}$ J Sports Med 2009;43:293-8.

6. Ryan MB, Wong AD, Gillies JH, et al. Sonographically guided intratendinous injections of hyperosmolar dextrose/lidocaine: a pilot study for the treatment of chronic plantar fasciitis. Br J Sports Med 2009:43:303-6.

7. van Leeuwen MT, Zwerver JC, van den AkkerScheek I. Extracorporeal shockwave therapy for patellar tendinopathy: a review of the literature. $\mathrm{Br} \mathrm{J}$ Sports Med 2009;43:163-8.

8. Paoloni JA, Murrell GAC, Burch RM, et al. Randomised, double-blind, placebo-controlled clinical trial of a new topical glyceryl trinitrate patch for chronic lateral epicondylosis. Br J Sports Med 2009;43:299-302.

9. Lewis JS. Rotator cuff tendinopathy/subacromial impingement syndrome: is it time for a new method of assessment? Br J Sports Med 2009;43:259-64.

10. Coombes BK, Bisset L, Vicenzino B. A new integrative model of lateral epicondylalgia. Br J Sports Med 2009;43:252-8.

11. Hegedus EJ, Goode A, Campbell S, et al. Physical examination tests of the shoulder: a systematic review with meta-analysis of individual tests. Br J Sports Med 2008;42:80-92. 